Article

\title{
Boronic Acids as Prospective Inhibitors of Metallo- $\beta$-Lactamases: Efficient Chemical Reaction in the Enzymatic Active Site Revealed by Molecular Modeling
}

\author{
Alexandra V. Krivitskaya ${ }^{1}$ and Maria G. Khrenova ${ }^{1,2, *(\mathbb{D})}$ \\ 1 Bach Institute of Biochemistry, Federal Research Centre "Fundamentals of Biotechnology" of the Russian \\ Academy of Sciences, 119071 Moscow, Russia; al_krivickaya@mail.ru \\ 2 Department of Chemistry, Lomonosov Moscow State University, 119991 Moscow, Russia \\ * Correspondence: mkhrenova@lcc.chem.msu.ru
}

Citation: Krivitskaya, A.V.; Khrenova, M.G. Boronic Acids as

Prospective Inhibitors of

Metallo- $\beta$-Lactamases: Efficient

Chemical Reaction in the Enzymatic Active Site Revealed by Molecular Modeling. Molecules 2021, 26, 2026. https://doi.org/10.3390/

molecules26072026

Academic Editor: Marko Goliĉnik

Received: 17 March 2021

Accepted: 1 April 2021

Published: 2 April 2021

Publisher's Note: MDPI stays neutral with regard to jurisdictional claims in published maps and institutional affiliations.

Copyright: (C) 2021 by the authors. Licensee MDPI, Basel, Switzerland. This article is an open access article distributed under the terms and conditions of the Creative Commons Attribution (CC BY) license (https:// creativecommons.org/licenses/by/ $4.0 /)$.

\begin{abstract}
Boronic acids are prospective compounds in inhibition of metallo- $\beta$-lactamases as they form covalent adducts with the catalytic hydroxide anion in the enzymatic active site upon binding. We compare this chemical reaction in the active site of the New Delhi metallo- $\beta$-lactamase (NDM- 1 ) with the hydrolysis of the antibacterial drug imipenem. The nucleophilic attack occurs with the energy barrier of $14 \mathrm{kcal} / \mathrm{mol}$ for imipenem and simultaneously upon binding a boronic acid inhibitor. A boron atom of an inhibitor exhibits stronger electrophilic properties than the carbonyl carbon atom of imipenem in a solution that is quantified by atomic Fukui indices. Upon forming the prereaction complex between NDM-1 and inhibitor, the lone electron pair of the nucleophile interacts with the vacant $p$-orbital of boron that facilitates the chemical reaction. We analyze a set of boronic acid compounds with the benzo[b]thiophene core complexed with the NDM-1 and propose quantitative structure-sroperty relationship (QSPR) equations that can predict IC50 values from the calculated descriptors of electron density. These relations are applied to classify other boronic acids with the same core found in the database of chemical compounds, PubChem, and proposed ourselves. We demonstrate that the IC50 values for all considered benzo[b]thiophene-containing boronic acid inhibitors are $30-70 \mu \mathrm{M}$.
\end{abstract}

Keywords: NDM-1; metallo- $\beta$-lactamase; bacterial resistance; benzo[b] thiophene; boronic acid inhibitor; QM/MM; QTAIM; QM/MM molecular dynamics

\section{Introduction}

Bacterial resistance is known from the very beginning of the penicillin era [1-4]. One of the mechanisms is attributed to the hydrolytic activity of the bacterial enzymes towards $\beta$-lactams. These enzymes are called $\beta$-lactamases (BLs), and they hydrolyze the C-N bond of the $\beta$-lactam ring of antibiotics forming the inactivated compounds, $\beta$-amino acids $[5,6]$. The antibiotic hydrolysis is initiated by various nucleophiles depending on the particular type of $\beta$-lactamases [6,7]. The B class BLs are metallo- $\beta$-lactamases (MBLs) that comprise one or two zinc cations in the active site [7]. These are divided into three subclasses, B1, B2, and B3 [8,9]. The most clinically relevant representative in the B1 subclass is the NDM-1 (New Delhi metallo- $\beta$-lactamase-1) [10]. It demonstrates substrate promiscuity [11], including hydrolysis of carbapenems [12]. In addition, it causes particular alertness due to its high spread between different bacterial species by lateral gene transfer favored by globalization and travel [13].

The active site of NDM- 1 contains two zinc cations, $\mathrm{Zn}^{2+}$ and $\mathrm{Zn} 2^{2+}$, bridged by a catalytic hydroxide ion, $\mathrm{OH}^{-}$. The first zinc cation $\left(\mathrm{Zn}^{2+}\right)$ is coordinated by His120, His122 and His189, while the second zinc cation $\left(\mathrm{Zn}^{2+}\right)$ is coordinated by Asp124, Cys208 and His250 (Figure 1A). In the binding site, $\mathrm{Zn} 1^{2+}$ orients and polarizes the carbonyl group of the substrate, facilitating the chemical reaction. The above-mentioned hydroxide anion is a 
nucleophile that initiates a chemical reaction by the attack on the $\beta$-lactam ring, eventually leading to substrate hydrolysis (Figure 1B) [8]. Since the discovery of NDM-1 [14], many inhibitors of various nature have been proposed. However, none of them has been clinically approved [8,15]. These are natural plant-based compounds [16,17], synthetic low molecular weight inhibitors [10,18-22], $\beta$-lactams [23-26], amino acid derivatives and peptides [27]. Boron-based inhibitors attract special attention [28-30]. Recent advances in developing the therapeutically relevant boron-containing compounds [31,32] even resulted in the FDAapproved anticancer drug bortezomib [33]. From the chemical viewpoint, these compounds are Lewis acids and can react reversibly with biologically relevant nucleophiles via their vacant $p$-orbitals [34-37]. They form covalent tetrahedral products, hydroxyboronate anions, upon reaction with the nucleophilic hydroxide anion in the active site of NDM-1 (Figure 1C) [18,35].

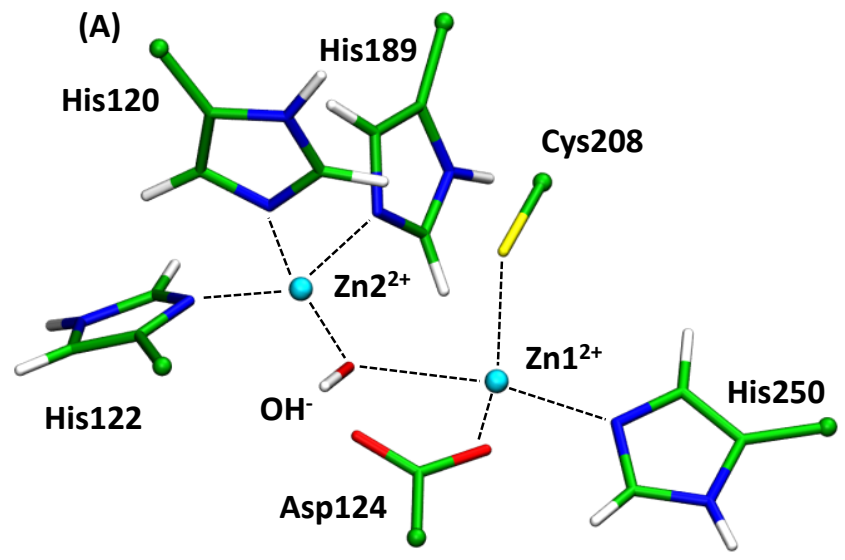

(B)

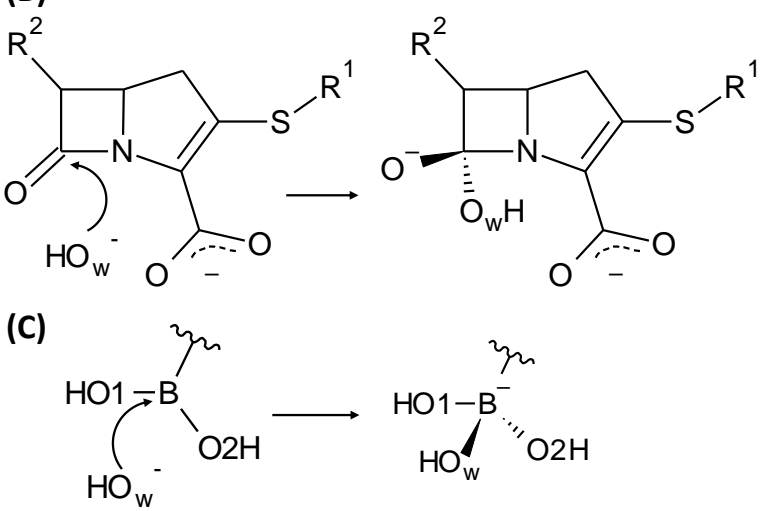

Figure 1. (A) The active site of NDM-1 metallo- $\beta$-lactamase (left). Nucleophilic attack step during (B) the hydrolysis of imipenem and $(C)$ conversion of boronic acid to hydroxyboronate anion. The $C_{B}$ atoms of the side chains of amino acids on the QM/MM border are shown in the ball's representation. Color code: zinc-cyan, oxygen-red, sulfur-yellow, nitrogen-blue, hydrogen-white; carbon is green in complexes with imipenem and lavender in complexes with cpd5.

In this work, we focus on two features of boron-containing inhibitors. First, we compare interactions between the nucleophilic $\mathrm{OH}^{-}$of the NDM-1 active site and its substrate imipenem with one of the boronic acid inhibitors (cpd5, according to Ref. [26]). To do this, we calculate the Gibbs energy profiles of the nucleophilic attack step using molecular dynamics (MD) simulations with the combined quantum mechanics/molecular mechanics QM(PBE0-D3/6-31G**)/MM potentials. Additionally, we compare the dynamic behavior of the corresponding reactant complexes with the same compounds in water solution, measuring atomic Fukui electrophilicity indices of the carbonyl carbon (in an imipenem) and boron (in a boronic acid inhibitor) atoms. Next, we consider five boronic acid inhibitors with the benzo[b]thiophene core with known IC50 values (concentration of inhibitor that results in 50\% inhibition of the enzyme activity) [26] corresponding to the NDM-1 inhibition. We study covalent adducts, hydroxyboronate anions in the active site of NDM-1 by analysis of equilibrium geometry configurations of the NDM-1 with these compounds and suggest electron density-based criteria responsible for the inhibitor potency. These features were calculated at the bond critical points determined in terms of the quantum theory of atoms in molecules (QTAIM) [38,39]. It was already shown that such an approach could explain macroscopic features of chemical reactions occurring in the active sites of enzymes [40-44]. We examined other known compounds with the same core and predicted their inhibition potency based on the correlation found for compounds with the known experimental IC50 values. 


\section{Models and Methods}

The model systems containing boronic acid inhibitors in the active site of NDM-1 were constructed using crystal structures PDB ID: 6IBV, 6Q2Y [35]. They corresponded to complexes of the NDM-1 with cpd2 and cpd3, respectively. The complexes with other experimentally studied boronic acid inhibitors, cpd1, cpd4 and cpd5 (Figure 2, compounds are numbered as in Ref. [26]) and other boronic acid-containing compounds with the benzo[b]thiophene core, cpd6-cpd15, were constructed by motifs of these X-ray structures. Substituted benzo[b]thiophene-containing boronic acids were found in the database of chemical compounds, PubChem (cpd6-cpd10, Figure 2) [45]. Additionally, we proposed ones with different electron-withdrawing groups (cpd11-cpd15, Figure 2).

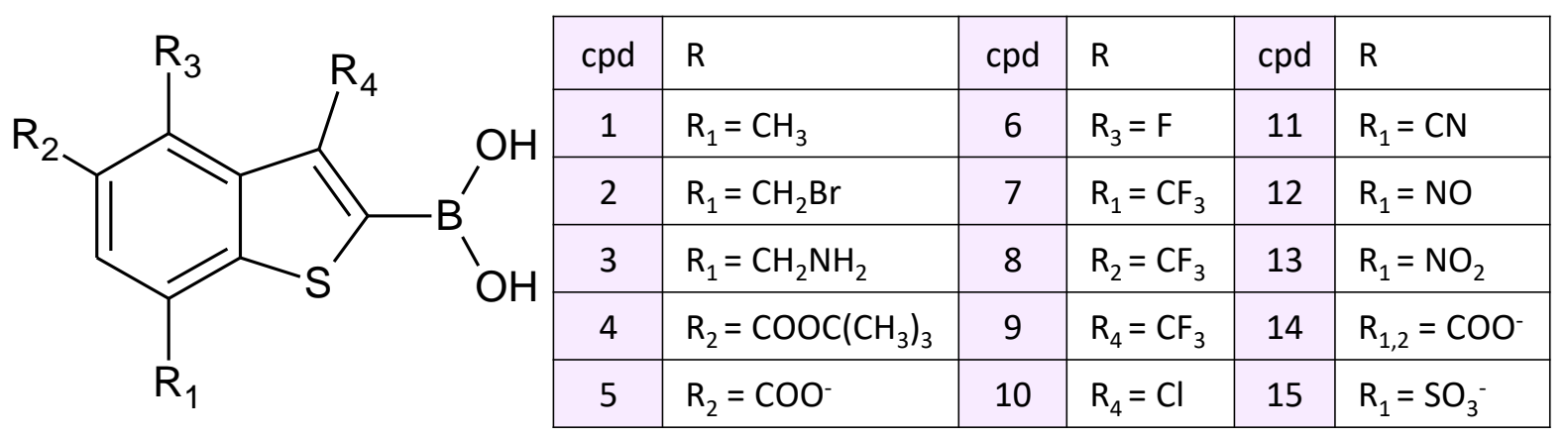

Figure 2. Boronic acid inhibitors considered in this study. Cpd1-cpd5 are experimentally studied in [26], cpd6-cpd10 are found in the PubChem [45] and cpd11-cpd15 are suggested in this study.

The enzyme-substrate complex of NDM-1 and imipenem was obtained from the crystal structure PDB ID: 5YPK [12] with the hydrolyzed imipenem bound to NDM-1. The structure of the imipenem was restored to its non-hydrolyzed state.

In all complexes, hydrogen atoms were added using the Reduce program [46] to reproduce the protonation states of amino acids at neutral $\mathrm{pH}$. The systems were solvated in rectangular water boxes so that the distance from the protein surface to the border of the cell exceeds $12 \AA$. These systems were neutralized by adding sodium or chloride ions. All atom force fields were utilized; CHARMM36 [47,48] for the protein, TIP3P [49] for water molecules and CGenFF [50] for the imipenem and inhibitors. Systems were equilibrated for $20 \mathrm{~ns}$; the typical RMSD graph is shown in Figure S1. It was performed at $\mathrm{T}=300 \mathrm{~K}$ and $p=1 \mathrm{~atm}$ with $1 \mathrm{fs}$ integration time step. The substrate/inhibitor, catalytic $\mathrm{OH}^{-}$, zinc cations, side chains of amino acids forming coordination bonds with $\mathrm{Zn}^{2+}$ and a side-chain of Asp124 were fixed during this preliminary run. All MD simulations were performed in the NAMD program [51]. Last frames from the MD runs were utilized for the subsequent preparation of the QM/MM models. Water molecules located further than $6 \AA$ from protein or $10 \AA$ from the active site and sodium/chloride ions were removed from the model systems. Equilibrium geometry configurations were obtained at the QM(PBE0D3/6-31G**)/MM(AMBER) [52-55] level of theory using the NWChem program [56]. An electronic embedding scheme was utilized with no cutoff on electrostatic interactions. The QM subsystem included the substrate or inhibitor, two $\mathrm{Zn}^{2+}$ cations and side chains of amino acid residues that form coordination bonds with them (His120, His122, His189, Cys208, His250), catalytic hydroxide anion and side chains of Asp124 and Asn220 that form hydrogen bonds with the substrate or inhibitor. Together, we obtained a set of 15 NDM-1 complexes with hydroxyboronate anion-containing compounds, EI.

Equilibrium geometry configurations of the NDM-1 with cpd5 (E.cpd5) and the ES complex after preliminary classical MD relaxation were utilized as initial structures for the molecular dynamics simulations with the QM/MM potentials. Solvation and neutralization of model systems, QM and MM partitioning and details of MD simulations are discussed above. The NAMD [51] program was utilized for MD steps performance and calculation of forces and energies of the MM subsystem. The TeraChem program [57] 
was used to calculate forces in the QM region, and a NAMD-TeraChem interface [58] was applied. The cutoff distance on the point charges of the MM subsystem contributing to the QM Hamiltonian was $12 \AA$. Gibbs energy profiles of the $\mathrm{OH}^{-}$nucleophilic attack were calculated using the umbrella sampling approach. For the ES model, the reaction coordinate was the distance between the carbonyl carbon atom of the imipenem and the oxygen atom of $\mathrm{OH}^{-}, \xi(\mathrm{ES})$ (Figure 3). Harmonic potentials $1 / 2 \cdot \mathrm{K} \cdot\left(\xi-\xi_{0}\right)^{2}$ were centered at $1.3,1.5$, $1.7,1.9,2.1,2.4,2.6$ and $2.8 \AA$ with the force constant $\mathrm{K}=40 \mathrm{kcal} /\left(\mathrm{mol} \cdot \AA^{2}\right)$; additional runs were performed with potentials centered at $1.7,1.8,1.9 \AA$ and $\mathrm{K}=80 \mathrm{kcal} /\left(\mathrm{mol} \cdot \AA^{2}\right)$; $1.7,1.8,1.9,2.0,2.1 \AA$ and $\mathrm{K}=120 \mathrm{kcal} /\left(\mathrm{mol} \cdot \AA^{2}\right)$. A complex collective variable was suggested as a reaction coordinate of the nucleophilic addition reaction in the E.cpd5 complex, $\xi(\mathrm{E} \cdot \mathrm{cpd} 5)$; it was set as a sum of two coordination bond distances, $\mathrm{d}\left(\mathrm{Zn} 2^{2+} \ldots\right.$ $\mathrm{O} 2)$ and $\mathrm{d}\left(\mathrm{Zn} 1^{2+} \ldots \mathrm{O} 1\right)$, and a distance of nucleophilic attack, $\mathrm{d}\left(\mathrm{B} \ldots \mathrm{O}_{\mathrm{w}}\right)$ (Figure 3). Harmonic potentials were centered at the following $\xi_{0}$ values: from $5.3 \AA$ to $10.4 \AA$ with $0.3 \AA$ increment, from $10.5 \AA$ to $10.8 \AA$ with $0.1 \AA$ increment, from $11.0 \AA$ to 11.6 with $0.2 \AA$ increment and $11.9 \AA$. The force constant was $40 \mathrm{kcal} /\left(\mathrm{mol} \cdot \AA^{2}\right)$ in all simulations. The reaction coordinates were analyzed between $5 \AA$ and $12 \AA$ and divided into 200 bins in the case of E·cpd5 and between $1.3 \AA$ and $3 \AA$ with 50 bins for the complex NDM-1imipenem complex. Each MD trajectory with additional harmonic potential added on the reaction coordinate was not less than 5 ps, and the first 1 ps was excluded from the data analysis. The weighted histogram analysis method (WHAM) was utilized to restore the Gibbs energy profile. The lengths of the QM/MM trajectories with harmonic potentials are considerably shorter than the conventional classical MD trajectories. However, we analyze the distributions that we obtain with each harmonic potential and check whether those changes with the further elongation of MD runs. Figures S2 and S3 depict distributions obtained with different harmonic potentials. MD trajectories of the comparable lengths were calculated in other enzymatic reaction mechanism studies; see, for example, Ref. [59]. Additional 10 ps runs were performed for the ES complex and E.cpd5 with the $\xi_{0}=10.1 \AA$ and $\mathrm{K}=40 \mathrm{kcal} /\left(\mathrm{mol} \cdot \AA^{2}\right)$ harmonic potential.

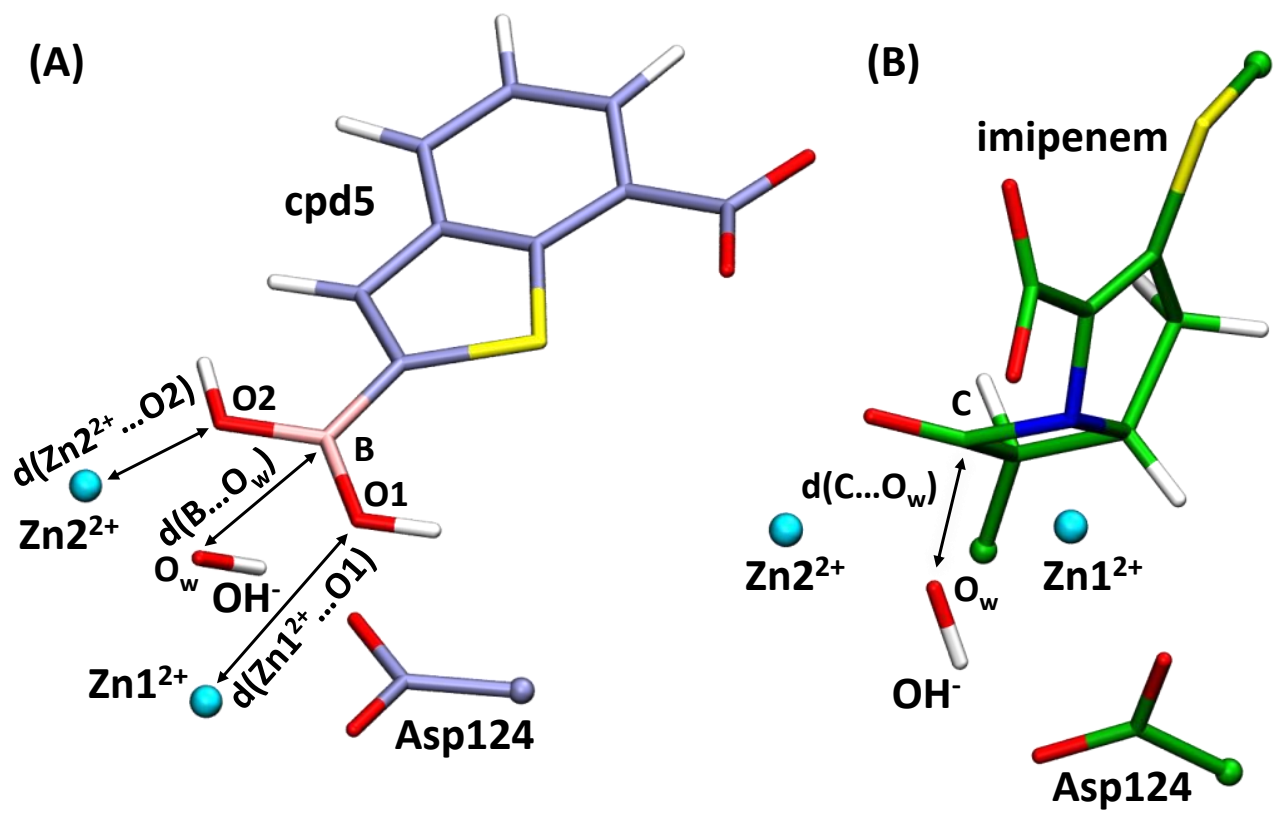

Figure 3. Complexes of NDM-1 and (A) cpd5, E.cpd5, or (B) imipenem, ES. Arrows indicate interatomic distances contributing to the reaction coordinate for the nucleophilic addition step. The reaction coordinates are $\xi(\mathrm{E} \cdot \mathrm{cpd} 5)=\mathrm{d}\left(\mathrm{Zn}^{2+} \ldots \mathrm{O} 2\right)+\mathrm{d}\left(\mathrm{Zn} 1^{2+} \ldots \mathrm{O} 1\right)+\mathrm{r}\left(\mathrm{B} \ldots \mathrm{O}_{\mathrm{w}}\right)$ on the left panel and $\xi(E S)=d\left(C \ldots O_{w}\right)$ on the right panel. For color code see Figure 1 caption. $C_{B}$ atoms of the Asp124 are shown in balls. The imipenem substrate is truncated for clarity: the carbon atoms on the truncation borders are shown in balls. 
Additional models were constructed for the cpd5 and imipenem (in the corresponding reactant states) solvated in the rectangular water box with the distance to the cell border being larger than $15 \AA$. The 1 ns preliminary classical MD simulation was performed before the $10 \mathrm{ps}$ QM/MM MD run. Computational protocols were the same as discussed above.

Analysis of all MD trajectories and visualization of the equilibrium geometry configurations were performed in the VMD program [60].

We performed an analysis of electron density-based and geometry descriptors at the stationary points on potential energy surfaces and along QM/MM trajectories. In the latter case, we selected a set of $100 \mathrm{MD}$ frames equally distributed along each considered MD trajectory. The electron densities were calculated, taking into account partial atomic charges from the MM subsystems that contributed to the one-electron part of the QM Hamiltonian. All electron density-based descriptors were calculated using the Multiwfn program [61]. We calculated electron density-based descriptors at bond-critical points (BCPs) corresponding to the coordination bonds between the zinc cations and hydroxyboronate anion-containing inhibitors (cpd1-cpd15) at minima on potential energy surfaces. These are electron density, $\rho(\mathrm{r})$, and Laplacian of electron density, $\nabla^{2} \rho(\mathrm{r})$. In addition, we calculate atomic contribution $S\left(\mathrm{r}, \Omega_{i}\right)$ [62-64] evaluated as

$$
S\left(\mathrm{r}, \Omega_{i}\right)=-\frac{1}{4 \pi} \int_{\Omega_{i}} \frac{\nabla^{2} \rho\left(\mathrm{r}^{\prime}\right)}{\left|\mathrm{r}-\mathrm{r}^{\prime}\right|} d \mathrm{r}^{\prime},
$$

where $\Omega_{i}$ is the atomic basin of the $i$-th atom; here, we consider oxygen atoms $\mathrm{O} 1, \mathrm{O} 2$ and $\mathrm{O}_{\mathrm{w}}$ that are covalently bound to a boron atom (Figure 1). More details on the utilization of electron density-based descriptors for biologically relevant systems are described in Refs. [41,43]. In the case of QM/MM MD trajectories, we calculated atomic Fukui electrophilicity indices, $\mathrm{f}+$, on a carbonyl carbon atom of the imipenem and a boron atom of cpd5. These are evaluated as differences between Hirshfeld charges [65] calculated for the model system with $\mathrm{N}$ electrons (as it is set in the calculations) and $\mathrm{N}+1$ electrons [66-68].

\section{Results and Discussion}

\subsection{Imipenem and Boronic Acid Inhibitor Cpd5 in Water Solution and in the Active Site of NDM-1}

The boronic acid inhibitors form covalent adducts with the catalytic $\mathrm{OH}^{-}$ion as known from the crystal structures [26]. Here, we study the mechanism of this chemical reaction and compare it with the same nucleophilic addition step during the hydrolysis reaction of the imipenem substrate.

First, we analyze the behavior of cpd5 and imipenem in solution in terms of the electrophilicity of the boron and carbon atoms that form covalent bonds with the $\mathrm{OH}^{-}$ during the reaction. We use the Fukui function for the electrophilic attack, $\mathrm{f}+$, calculated for the C (in the imipenem) and B (in the cpd5) atoms along the MD trajectories (Figure 4). The $\mathrm{f}+$ distribution is considerably shifted to the larger values in the case of $\mathrm{B}$, indicating that it is a stronger nucleophile in the solution. The $\mathrm{f}+$ value for the carbonyl carbon atom in the imipenem is $0.032 \pm 0.015$ a.u. and $0.074 \pm 0.011$ a.u. for B of the cpd5. 


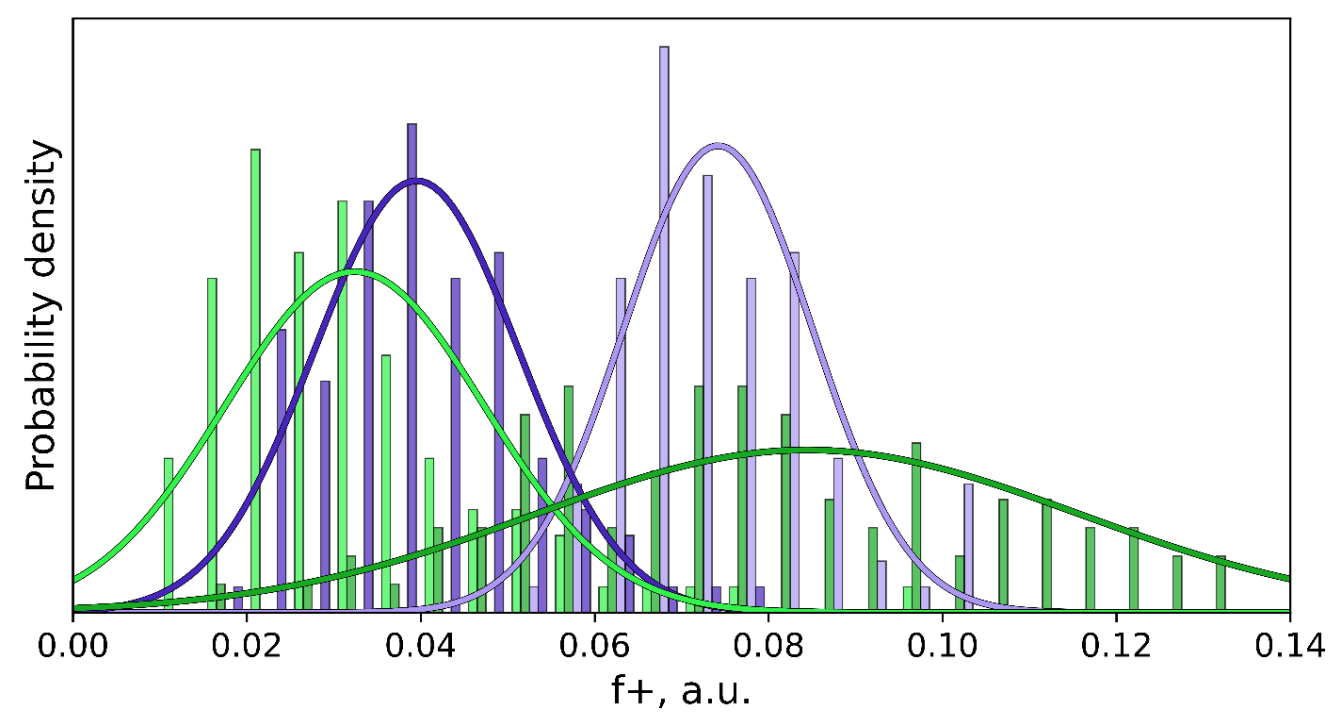

Figure 4. Distributions of Fukui electrophilicity indices, $\mathrm{f}+$, on the carbonyl carbon atom of the imipenem (green) and boron atom of the cpd5 (violet) along the molecular dynamics trajectories with the combined quantim mechanics molecular mechanics potentials, QM/MM MD. Light colors correspond to the compounds in aqueous solutions, and dark colors are for the NDM-1 bound states. Corresponding normal distributions are shown in the same colors.

Next, we study the behavior of these two compounds in the active site of NDM-1. We constructed the ES complex with an imipenem molecule. During the QM/MM MD simulation, the distance of the nucleophilic attack varied in the range of $2.89 \pm 0.15 \AA$. The mean value of the $\mathrm{f}+(\mathrm{C})$ increases more than twice compared with water solution being 0.084 a.u (Figure 4). This distribution is considerably broader, with the standard deviation being 0.031 a.u. that is twice larger than in solution. It means that not all ES complexes (frames along the MD trajectory) correspond to the reactive species. The fraction with the larger $f+$ values demonstrates the substrate activation in the active site of the enzyme discussed in Refs. $[59,69]$. The Gibbs energy profile for the nucleophilic attack step was calculated using the umbrella sampling technique (Figure 5). The minimum corresponding to the ES complex is located at the reaction coordinate value of $2.79 \AA$. It is slightly shorter than the mean $\mathrm{C} \ldots \mathrm{O}_{\mathrm{w}}$ distance along the MD trajectory of the ES complex. During the unconstrained MD simulation of the ES complex, we observe both reactive and nonreactive species, whereas only reactive species contribute to the chemical reaction [43]. The C ... $\mathrm{O}_{\mathrm{w}}$ distance at the transition state is $1.92 \AA$ that is typical for this type of reaction occurring in the zinc-dependent proteins. To compare, it is $1.86 \AA$ in the case of nitrocefin hydrolysis by L1 metallo- $\beta$-lactamase [70] and $1.80 \AA$ during the oligopeptide hydrolysis by MMP- 2 matrix metalloproteinase [71]. The energy barrier at this step is about $14 \mathrm{kcal} / \mathrm{mol}$, and the first intermediate, Int, is $\sim 4 \mathrm{kcal} / \mathrm{mol}$ higher in energy than the ES complex.
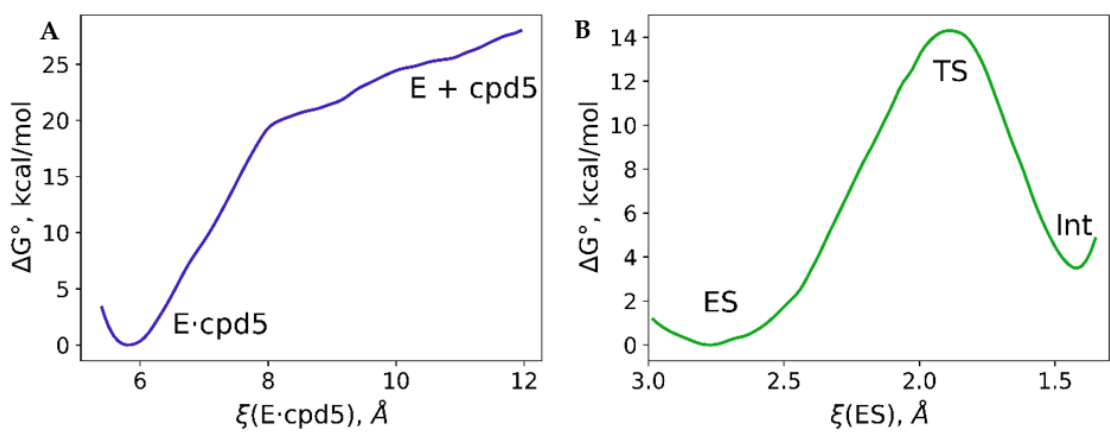

Figure 5. Gibbs energy profiles of the nucleophilic attack step in the active site of NDM-1 calculated (A) for the boronic acid-based inhibitor cpd5 and (B) for the imipenem substrate. The description of the reaction coordinate is shown in Figure 3 and in the Methods section. 
The Gibbs energy profile of the covalent bond formation between the $\mathrm{OH}^{-}$and the cpd5 was studied within the same QM/MM protocol. First, we performed the QM/MM $\mathrm{MD}$ run of the product state (E.cpd5) with the covalent bond between the cpd5 and $\mathrm{OH}^{-}$. We gradually increased the reaction coordinate and performed sequential umbrella sampling runs. The first attempt was a simple reaction coordinate, $d\left(B \ldots \mathrm{O}_{w}\right)$, similarly to the reaction with the imipenem. However, this resulted in the artificial behavior of the model system. Therefore, we proposed a more complex reaction coordinate that accounts not only for the distance of nucleophilic attack but also for two coordination bonds between oxygen atoms, $\mathrm{O} 1$ and $\mathrm{O} 2$, of the cpd5 and zinc cations (Figure 3). The reaction coordinate equals $5.8 \AA$ at the minimum, corresponding to the covalent complex E.cpd5 with two coordination bonds, $\mathrm{Zn}_{1}{ }^{2+} \ldots \mathrm{O} 1$ and $\mathrm{Zn} 2^{2+} \ldots \mathrm{O} 2$, and a covalent $\mathrm{B}-\mathrm{O}_{\mathrm{w}}$ bond being formed. The dissociation energy profile has two regions. A smaller reaction coordinate values, the rapid increase of energy results in the cleavage of the covalent bond $\mathrm{B}-\mathrm{O}_{\mathrm{w}}$ and elongation of coordination bonds. Starting from the $\xi=8 \AA$, the energy increases much slower; the covalent bond is already cleaved, and the dissociation process is mostly related to the complete cleavage of coordination bonds. One should keep in mind that even at the $\xi=12 \AA$, the NDM- 1 and cpd5 complex is not fully dissociated. More precisely, the coordination bonds between the cpd 5 and zinc cations are cleaved, but components of this complex are not fully solvated. We expect that at larger $\xi$ values, the Gibbs energy will decrease.

We failed to obtain a stable prereaction complex of the NDM-1 and the cpd5. However, we analyzed the dynamic behavior of the system in the geometry configuration that is similar to the ES complex. We performed a constrained MD run with the $\xi_{0}=10.1 \AA$ and the force constant imposed on the reaction coordinate $\mathrm{K}=40 \mathrm{kcal} /\left(\mathrm{mol} \cdot \AA^{2}\right)$. The B ... $\mathrm{O}_{\mathrm{w}}$ distance varied in the range of $2.97 \pm 0.13 \AA$. We expected that the $\mathrm{f}+$ on the boron atom is higher than in the solution. However, it turned out that it was considerably smaller and similar to that of a carbon atom of imipenem in the solution being $0.040 \pm 0.012$ a.u. (Figure 4). To analyze this unexpected phenomenon, we calculated the Laplacian of electron density, $\nabla^{2} \rho(\mathrm{r})$, along the $\mathrm{C} \ldots \mathrm{O}_{\mathrm{w}}$ and $\mathrm{B} \ldots \mathrm{O}_{\mathrm{w}}$ at different frames. Figure 6 demonstrates the alignment of $\nabla^{2} \rho(\mathrm{r})$ for complexes of the NDM-1 with the cpd5 or the imipenem with the same distances of the nucleophilic attack. The $\nabla^{2} \rho(\mathrm{r})$ curves are similar around the oxygen atom of the $\mathrm{OH}^{-}$and are different in the $\mathrm{B} / \mathrm{C}$ region. In the case of a carbon atom, we observe a minimum at $\sim 0.5 \AA$ and a maximum at $\sim 0.7 \AA$ from a $C$ nucleus. In the case of a boron atom, we observe a flat region between two atoms with the small deconcentration of electron density $\left(\nabla^{2} \rho(\mathrm{r})>0\right)$.

We analyzed the $\nabla^{2} \rho(\mathrm{r})$ curves at different MD frames. For different NDM-1 with cpd5 complexes, we observe similar behavior of the Laplacian of electron density in the interatomic region: a flat area with the electron density deconcentration, with $\nabla^{2} \rho(\mathrm{r})$ being around 0.05 a.u. Such regions are attributed to the presence of the substrate activation effect that was previously demonstrated on the 2D maps of $\nabla^{2} \rho(\mathrm{r})[42,43,69,72]$. From this viewpoint, the boron atom is activated in all presented MD frames. However, its Fukui electrophilicity index is lower when bound to NDM-1 compared with the aqueous solution. Similar abnormal behavior of a boron atom is discussed in Ref. [73] and it is attributed to the strong $p-\pi$ electronic interactions; that is, the empty $p$-orbital of a boron center is partly filled by the $\pi$-electron of the neighboring atom. In our case, the partner of these interactions is a nucleophilic $\mathrm{OH}^{-}$that partly "donates" its electron lone pair to the empty boron $p$-orbital. It seems that these interactions, together with the long-range electrostatic interactions between the coordination bond partners, may be the reason for the failure to locate a minimum corresponding to the prereaction complex.

Laplacian of electron density curves for the ES complex at different MD frames are diverse. Depending on the particular frame, a minimum that is $0.5 \AA$ apart from a carbon atom has either a positive (solid green line on Figure 6) or negative (green dashed line on Figure 6) $\nabla^{2} \rho(\mathrm{r})$ value. It means that a substrate is activated only at certain frames. It is in line with the presence of equilibrium between the reactive and nonreactive species [43]. 


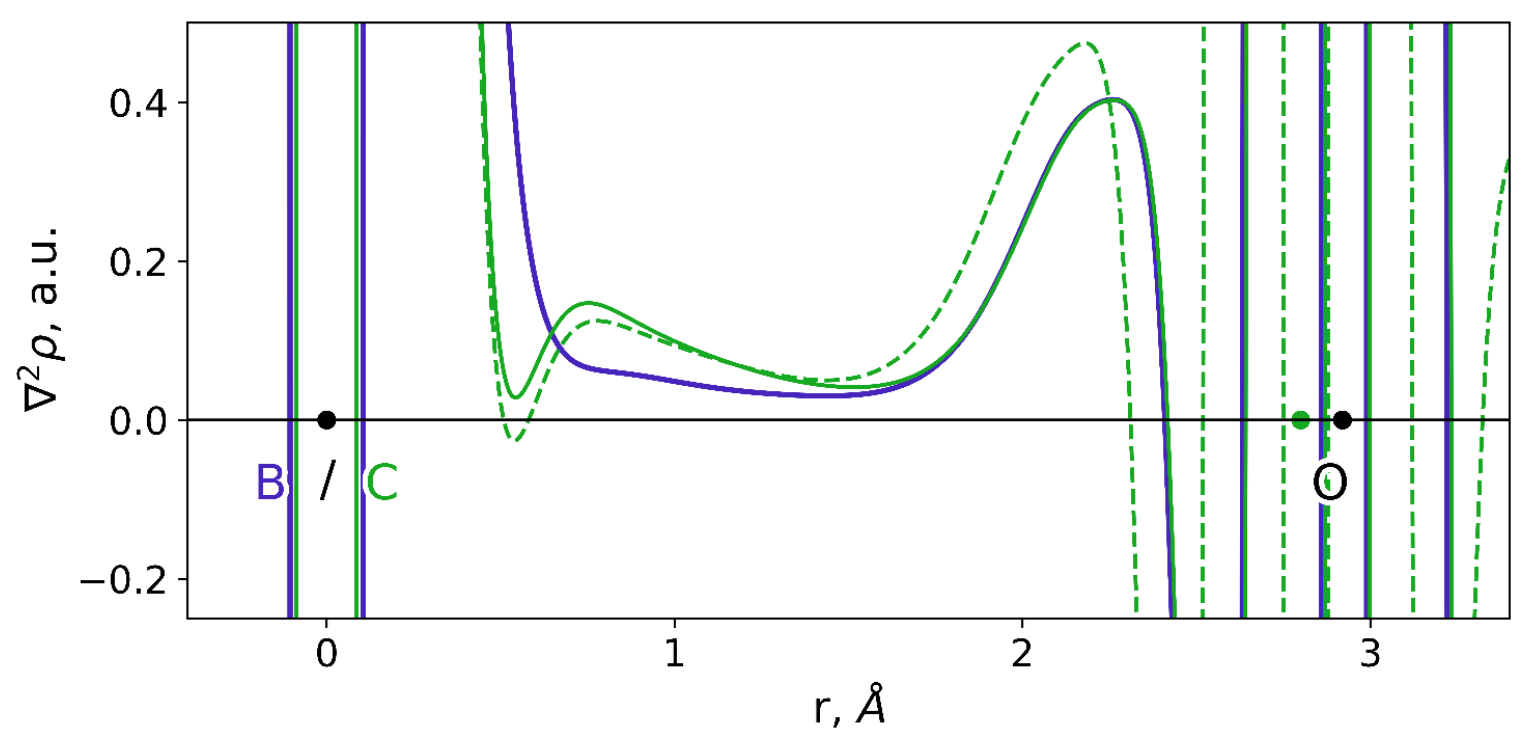

Figure 6. Laplacian of electron density, $\nabla^{2} \rho(\mathrm{r})$, along the $\mathrm{C} / \mathrm{B} \ldots \mathrm{O}_{\mathrm{w}}$ direction of the nucleophilic attack. Solid curves correspond to the NDM-1-imipenem (green) and NDM-1-cpd5 (violet) with the same distance of nucleophilic attack. The dashed green curve corresponds to another snapshot along the NDM-1-imipenem complex QM/MM MD trajectory. Boron and carbon atoms are always located at the $r=0 \AA$ value; an oxygen atom is shown in black if it occupies the same position for complexes with both imipenem and cpd5 and colored green for another ES snapshot with the $\nabla^{2} \rho(\mathrm{r})$ shown in green dashed line.

\subsection{Interatomic Interactions Responsible for the Inhibition Potency}

Another important issue is the prediction of the inhibitor potency of boronic acid compounds. We calculated equilibrium geometry configurations for a set of covalent complexes of NDM-1 and hydroxyboronate anion-containing compounds with available experimental IC50 values [26]. All complexes demonstrate similar geometry features. The length of the newly formed covalent bond between a boron-based inhibitor and a former nucleophilic hydroxide anion, $\mathrm{B}-\mathrm{O}_{\mathrm{w}}$, is $1.45-1.49 \AA$ А; covalent $\mathrm{B}-\mathrm{O} 1$ and $\mathrm{B}-\mathrm{O} 2$ bonds lengths are distributed similarly. Coordination bonds, $\mathrm{Zn}^{2+} \ldots \mathrm{O}_{\mathrm{w}}, \mathrm{Zn} 1^{2+} \ldots$ O1 and $\mathrm{Zn} 2^{2+}$.. O O2 are 1.94-1.96,, $2.32-2.51 \AA$ and $1.95-2.03 \AA$, respectively (Table 1 , Figure 3). Here, the QTAIM $[38,39]$ is utilized to identify and characterize interatomic interactions. It was already demonstrated that even in large systems, such as enzymes, one could identify key interatomic interactions that are responsible for the observed macroscopic property [41]. The first step in the search of key interatomic interactions is interatomic distances check. Geometry parameters demonstrate a worse correlation. However, if these exist, this can be the hint for electron density-based descriptor search. We found that electron density-based descriptors at the bond critical points (BCPs) of the coordination bonds between the hydroxyboronate anion and zinc cations correlate with the IC50 values (Table 1, Figure 7). These are $\mathrm{Zn} 1^{2+} \ldots \mathrm{O} 1, \mathrm{Zn}^{2+} \ldots \mathrm{O} 2$ and $\mathrm{Zn} 1^{2+} \ldots \mathrm{O}_{\mathrm{w}}$ coordination bonds with the corresponding BCP1, BCP2 and BCP3. We obtained QSPR equations between the IC50 values and coordination bond length, electron density at $\mathrm{BCP}$, Laplacian of electron density at $\mathrm{BCP}$ and atomic contribution of an oxygen atom forming coordination bond to a corresponding BCP (Table 1). Sums of corresponding values at $\mathrm{BCP} 1, \mathrm{BCP} 2$ and $\mathrm{BCP} 3$ were also examined. The best correlations were obtained for the IC50 dependency on the atomic contributions at BCP and sums of descriptors calculated at three BCPs. These QSPR equations were further utilized for the prediction of the IC50 values of new compounds. 
Table 1. Characteristics of linear dependences between descriptors at BCPs of coordination bonds and experimental IC50 values. The slope units are reciprocal descriptor units multiplied by $\mu \mathrm{M}$. The $\Sigma$ subscript in the last three rows corresponds to the sum of corresponding descriptors at BCP1, BCP2 and BCP3 that are located on the bond paths between $\mathrm{Zn} 1^{2+}$ and $\mathrm{O} 1$, $\mathrm{Zn} 2^{2+}$ and $\mathrm{O} 2, \mathrm{Zn}^{2+}$ and $\mathrm{O}_{\mathrm{w}}$, respectively. RSS is the residual sum of squares.

\begin{tabular}{|c|c|c|c|c|c|c|}
\hline Descriptor & $\begin{array}{c}\text { Descriptor } \\
\text { Range }\end{array}$ & Slope & Intercept, $\mu \mathrm{M}$ & $\mathbf{R}^{2}$ & Error, $\mu \mathbf{M}$ & RSS, $\mu \mathbf{M}^{-2}$ \\
\hline $\mathrm{d}\left(\mathrm{Zn} 1^{2+} \ldots \mathrm{O} 1\right), \AA$ & $2.32-2.51$ & $184 \pm 41$ & $-397 \pm 100$ & 0.827 & 195-203 & 150 \\
\hline$\rho\left(\mathrm{r}_{\mathrm{BCP} 1}\right)$, a.u. & $0.025-0.038$ & $-2667 \pm 618$ & $131 \pm 19$ & 0.815 & $34-42$ & 160 \\
\hline$\nabla^{2} \rho\left(\mathrm{r}_{\mathrm{BCP} 1}\right)$, a.u. & $0.11-0.17$ & $-644 \pm 159$ & $137 \pm 21$ & 0.793 & $39-48$ & 179 \\
\hline $\mathrm{S}\left(\mathrm{r}_{\mathrm{BCP} 1}, \mathrm{O} 1\right)$, a.u. & $0.0018-0.0081$ & $-5489 \pm 1238$ & $74 \pm 6$ & 0.823 & $8-16$ & 153 \\
\hline $\mathrm{d}\left(\mathrm{Zn} 2^{2+} \ldots \mathrm{O} 2\right), \AA$ & $1.95-2.03$ & $415 \pm 51$ & $-778 \pm 102$ & 0.942 & $202-206$ & 50 \\
\hline$\rho\left(\mathrm{r}_{\mathrm{BCP} 2}\right)$, a.u. & $0.072-0.094$ & $-1643 \pm 259$ & $183 \pm 21$ & 0.908 & $39-45$ & 80 \\
\hline$\nabla^{2} \rho\left(\mathrm{r}_{\mathrm{BCP} 2}\right)$, a.u. & $0.28-0.34$ & $-602 \pm 102$ & $234 \pm 31$ & 0.894 & $60-66$ & 92 \\
\hline $\mathrm{S}\left(\mathrm{r}_{\mathrm{BCP} 2}, \mathrm{O} 2\right)$, a.u. & $0.026-0.036$ & $-3413 \pm 432$ & $152 \pm 13$ & 0.939 & $24-28$ & 53 \\
\hline $\mathrm{d}\left(\mathrm{Zn} 1^{2+} \ldots \mathrm{O}_{\mathrm{w}}\right), \AA$ & $1.94-1.96$ & $1094 \pm 640$ & $-2088 \pm 1251$ & 0.325 & $2490-2507$ & 583 \\
\hline$\rho\left(\mathrm{r}_{\mathrm{BCP} 3}\right)$, a.u. & $0.088-0.094$ & $-3348 \pm 3930$ & $354 \pm 354$ & - & $700-723$ & 927 \\
\hline$\nabla^{2} \rho\left(\mathrm{r}_{\mathrm{BCP} 3}\right)$, a.u. & $0.33-0.36$ & $-1207 \pm 569$ & $458 \pm 191$ & 0.467 & $378-393$ & 461 \\
\hline $\mathrm{S}\left(\mathrm{r}_{\mathrm{BCP} 3}, \mathrm{O}_{\mathrm{w}}\right)$, a.u. & $0.033-0.036$ & $-8964 \pm 5351$ & $352 \pm 179$ & 0.311 & $353-370$ & 595 \\
\hline$\rho_{\Sigma}$, a.u. & $0.19-0.22$ & $-1017 \pm 114$ & $255 \pm 23$ & 0.952 & $44-48$ & 42 \\
\hline$\nabla^{2} \rho_{\Sigma}$, a.u. & $0.72-0.84$ & $-292 \pm 26$ & $277 \pm 20$ & 0.968 & $39-43$ & 28 \\
\hline $\mathrm{S}_{\Sigma}$, a.u. & $0.060-0.078$ & $-1979 \pm 192$ & $184 \pm 13$ & 0.964 & $24-28$ & 31 \\
\hline
\end{tabular}

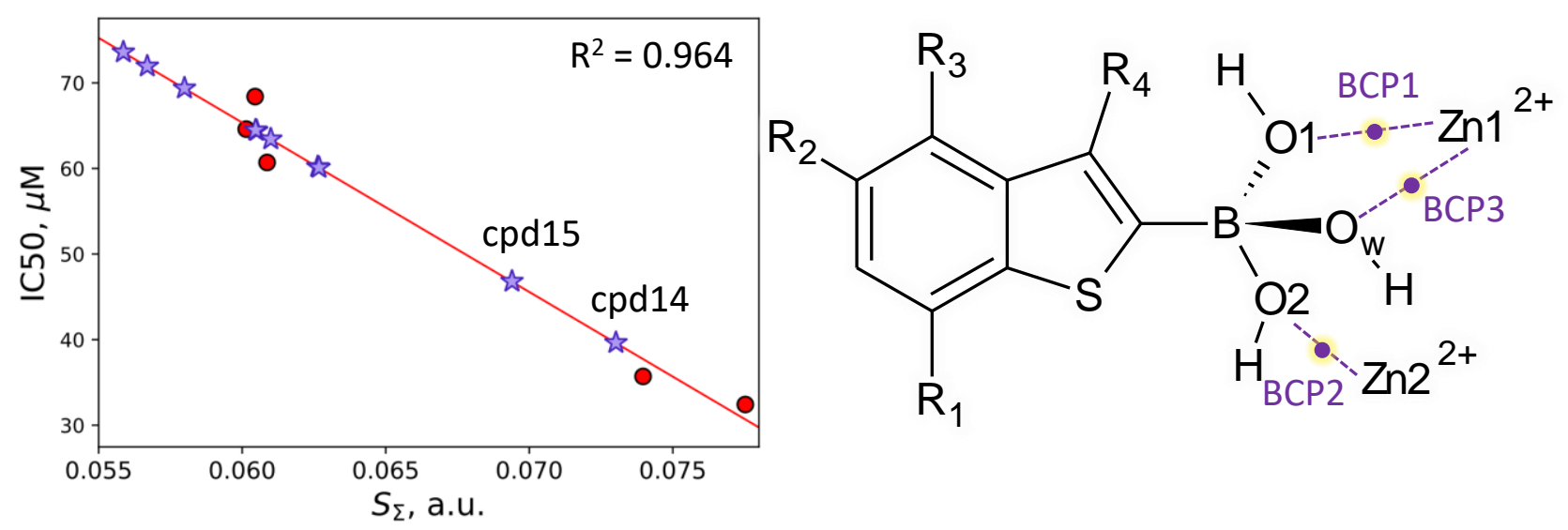

Figure 7. The IC50 $=\mathrm{f}\left(\mathrm{S}_{\Sigma}\right)$ dependency; red dots correspond to cpd1-cpd5 inhibitors; cpd6-cpd15 are marked with lavender stars. Prospective compounds, cpd14 and cpd15, are named. Coordination bonds between the hydroxyboronate anion and zinc cations are shown with violet dashed lines, and corresponding bond critical points (BCPs) are highlighted yellow.

NDM-1 complexes were modeled with compounds cpd6-cpd10 presented in the PubChem [45] and having the same benzo[b]thiophene core. However, their predicted IC50 values were found to be higher than $60 \mu \mathrm{M}$. Therefore, we returned to the experimentally studied set. The cpd5 has the lowest value of IC50 among those studied experimentally, so it was chosen as a lead compound to design new inhibitors. Namely, we proposed that electron-withdrawing groups are responsible for the IC50 value. We suggested and examined another set of compounds (cpd11-cpd15), replacing the carboxyl group in cpd5 with other electron-withdrawing groups or adding them at different positions. All of them demonstrated IC50 values in the same range. Among them, the most promising are cpd14 
and cpd15 (Figure 2), which have predicted IC50 values $40 \mu \mathrm{M}$ and $47 \mu \mathrm{M}$, respectively (Figure 7). It seems that a further decrease of the IC50 value can be achieved if changing the core of boronic acid compounds.

\section{Conclusions}

Application of molecular dynamics simulations with the QM/MM potentials complemented with on-the-fly calculations of electron density-based descriptors allowed us to study and compare nucleophilic attacks of the catalytic species in the NDM-1 active site. We compared the reaction mechanism with a substrate imipenem and a boronic acid inhibitor. The nucleophilic attack occurs with the energy barrier of $14 \mathrm{kcal} / \mathrm{mol}$ in the case of the imipenem and simultaneously upon binding of an inhibitor. Activation of the carbonyl carbon atom of the imipenem is observed in the enzyme-substrate. The boronic acid compound is already activated, even being surrounded by water molecules. These properties are quantified by the atomic Fukui electrophilicity indices. Binding to the active site of NDM-1 comprises both formations of the prereaction interactions between the boron atom of an inhibitor and a catalytic $\mathrm{OH}^{-}$and coordination bonds between $\mathrm{OH}$ groups of an inhibitor and zinc cations. The latter interactions are predominantly of an electrostatic nature and are long-range. Upon the formation of the prereaction complex between NDM-1 and inhibitor, the lone electron pair of the nucleophile interacts with the vacant $p$-orbital of boron that facilitates the chemical reaction. This explains the barrierless process of covalent bond formation between an $\mathrm{OH}^{-}$and a boronic acid if a latter comes to the active site of NDM-1.

We analyzed a set of boronic acid compounds with the benzo[b]thiophene core complexed with the NDM-1 and proposed QSPR equations to predict IC50 values from the calculated descriptors of electron density. Among them, the prospective ones are quantities obtained as sums of electron densities, Laplacian of electron densities or atomic contributions calculated at BCPs of three coordination bonds between oxygen atoms of hydroxyboronate anion and zinc cations. We examined a set of compounds with the same benzo[b]thiophene from the PubChem database and proposed others ourselves. The predicted IC50 values were found to be larger than $30 \mu \mathrm{M}$, similar to those studied experimentally. We suppose that a further decrease of this value can be achieved if changing the core of boronic acid compounds.

Supplementary Materials: The following are available online, Figure S1: RMSD along the classical MD trajectory, Figures S2 and S3: reaction coordinate distributions along the QM/MM MD simulations with the harmonic potentials.

Author Contributions: Conceptualization, M.G.K.; methodology, M.G.K., A.V.K.; data curation, M.G.K.; writing—original draft preparation, M.G.K., A.V.K.; validation, M.G.K., A.V.K.; visualization, M.G.K., A.V.K.; supervision, M.G.K.; project administration, M.G.K.; funding acquisition, M.G.K. Both authors have read and agreed to the published version of the manuscript.

Funding: $\mathrm{QM} / \mathrm{MM}$ and $\mathrm{QM} / \mathrm{MM}$ MD simulations in the active site of NDM-1 were supported by Russian Science Foundation (project No 18-74-10056). The QM/MM MD simulations of compounds under consideration in water solutions were supported by the Ministry of Science and Higher Education of the Russian Federation. The research is carried out using the equipment of the shared research facilities of HPC computing resources at Lomonosov Moscow State University and Joint Supercomputer Center of the Russian Academy of Sciences.

Data Availability Statement: Equilibrium geometry configurations of EI complexes are available at the ZENODO at https:/ / doi.org/10.5281/zenodo.4606675 (accessed on 1 April 2021).

Conflicts of Interest: The authors declare no conflict of interest.

\section{References}

1. Abraham, E.P.; Chain, E. An Enzyme from Bacteria able to Destroy Penicillin. Nature 1940, 146, 837. [CrossRef]

2. Drawz, S.M.; Bonomo, R.A. Three Decades of $\beta$-Lactamase Inhibitors. Clin. Microbiol. Rev. 2010, 23, 160-201. [CrossRef] 
3. Lagadinou, M.; Onisor, M.O.; Rigas, A.; Musetescu, D.-V.; Gkentzi, D.; Assimakopoulos, S.F.; Panos, G.; Marangos, M. Antimicrobial Properties on Non-Antibiotic Drugs in the Era of Increased Bacterial Resistance. Antibiotics 2020, 9, 107. [CrossRef] [PubMed]

4. Corrêa, R.C.G.; Heleno, S.A.; Alves, M.J.; Ferreira, I.C.F.R. Bacterial Resistance: Antibiotics of Last Generation used in Clinical Practice and the Arise of Natural Products as New Therapeutic Alternatives. Curr. Pharm. Des. 2020, 26, 815-837. [CrossRef]

5. Munita, J.M.; Arias, C.A. Mechanisms of Antibiotic Resistance. Microbiol. Spectr. 2016, 4. [CrossRef] [PubMed]

6. Hall, B.G.; Barlow, M. Revised Ambler classification of $\beta$-lactamases. J. Antimicrob. Chemother. 2005, 55, 1050-1051. [CrossRef] [PubMed]

7. Levina, E.O.; Khrenova, M.G. Metallo- $\beta$-Lactamases: Influence of the Active Site Structure on the Mechanisms of Antibiotic Resistance and Inhibition. Biochemistry 2021, 86, S24-S37. [CrossRef]

8. Mojica, M.F.; Bonomo, R.A.; Fast, W. B1-Metallo- $\beta$-Lactamases: Where Do We Stand? Curr. Drug Targets 2016, 17, 1029-1050. [CrossRef]

9. Palzkill, T. Metallo- $\beta$-lactamase structure and function. Ann. N. Y. Acad. Sci. 2013, 1277, 91-104. [CrossRef]

10. Linciano, P.; Cendron, L.; Gianquinto, E.; Spyrakis, F.; Tondi, D. Ten Years with New Delhi Metallo- $\beta$-lactamase-1 (NDM-1): From Structural Insights to Inhibitor Design. ACS Infect. Dis. 2019, 5, 9-34. [CrossRef]

11. Kim, Y.; Cunningham, M.A.; Mire, J.; Tesar, C.; Sacchettini, J.; Joachimiak, A. NDM-1, the ultimate promiscuous enzyme: Substrate recognition and catalytic mechanism. FASEB J. 2013, 27, 1917-1927. [CrossRef] [PubMed]

12. Feng, H.; Liu, X.; Wang, S.; Fleming, J.; Wang, D.-C.; Liu, W. The mechanism of NDM-1-catalyzed carbapenem hydrolysis is distinct from that of penicillin or cephalosporin hydrolysis. Nat. Commun. 2017, 8, 2242. [CrossRef] [PubMed]

13. Rolain, J.M.; Parola, P.; Cornaglia, G. New Delhi metallo-beta-lactamase (NDM-1): Towards a new pandemia? Clin. Microbiol. Infect. 2010, 16, 1699-1701. [CrossRef] [PubMed]

14. Isozumi, R.; Yoshimatsu, K.; Yamashiro, T.; Hasebe, F.; Nguyen, B.M.; Ngo, T.C.; Yasuda, S.P.; Koma, T.; Shimizu, K.; Arikawa, J. bla $a_{\mathrm{NDM}-1}$-positive Klebsiella pneumoniae from Environment, Vietnam. Emerg. Infect. Dis. 2012, 18, 1383-1385. [CrossRef]

15. Liang, Z.; Li, L.; Wang, Y.; Chen, L.; Kong, X.; Hong, Y.; Lan, L.; Zheng, M.; Guang-Yang, C.; Liu, H.; et al. Molecular Basis of NDM-1, a New Antibiotic Resistance Determinant. PLoS ONE 2011, 6, e23606. [CrossRef]

16. Horie, R.; Hazbun, A.; Chen, K.; Cao, C.; Levine, M.; Horie, T. Shared evolutionary origin of vertebrate neural crest and cranial placodes. Nature 2018, 560, 228-232. [CrossRef] [PubMed]

17. Wang, Y.; Sun, X.; Kong, F.; Xia, L.; Deng, X.; Wang, D.; Wang, J. Specific NDM-1 Inhibitor of Isoliquiritin Enhances the Activity of Meropenem against NDM-1-positive Enterobacteriaceae in vitro. Int. J. Environ. Res. Public Health 2020, 17, 2162. [CrossRef] [PubMed]

18. Hecker, S.J.; Reddy, K.R.; Lomovskaya, O.; Griffith, D.C.; Rubio-Aparicio, D.; Nelson, K.; Tsivkovski, R.; Sun, D.; Sabet, M.; Tarazi, Z.; et al. Discovery of Cyclic Boronic Acid QPX7728, an Ultrabroad-Spectrum Inhibitor of Serine and Metallo- $\beta$-lactamases. J. Med. Chem. 2020, 63, 7491-7507. [CrossRef]

19. Chen, C.; Liu, Y.; Zhang, Y.-J.; Ge, Y.; Lei, J.-E.; Yang, K.-W. The assemblage of covalent and metal binding dual functional scaffold for cross-class metallo- $\beta$-lactamases inhibition. Future Med. Chem. 2019, 11, 2381-2394. [CrossRef] [PubMed]

20. Leiris, S.; Coelho, A.; Castandet, J.; Bayet, M.; Lozano, C.; Bougnon, J.; Bousquet, J.; Everett, M.; Lemonnier, M.; Sprynski, N.; et al. SAR Studies Leading to the Identification of a Novel Series of Metallo- $\beta$-lactamase Inhibitors for the Treatment of CarbapenemResistant Enterobacteriaceae Infections That Display Efficacy in an Animal Infection Model. ACS Infect. Dis. 2019, 5, 131-140. [CrossRef] [PubMed]

21. Yuan, C.; Yan, J.; Song, C.; Yang, F.; Li, C.; Wang, C.; Su, H.; Chen, W.; Wang, L.; Wang, Z.; et al. Discovery of [1,2,4]Triazole Derivatives as New Metallo- $\beta$-Lactamase Inhibitors. Molecules 2019, 25, 56. [CrossRef]

22. Zhang, Y.; Yan, Y.; Liang, L.; Feng, J.; Wang, X.; Li, L.; Yang, K. Halogen-Substituted Triazolethioacetamides as a Potent Skeleton for the Development of Metallo- $\beta$-Lactamase Inhibitors. Molecules 2019, 24, 1174. [CrossRef] [PubMed]

23. Li, Z.; Lu, X.; Wang, Y.; Hu, X.; Fu, H.; Gao, L.; You, X.; Tang, S.; Song, D. Synthesis and antibacterial evaluation against resistant Gram-negative bacteria of monobactams bearing various substituents on oxime residue. Bioorg. Chem. 2020, 94 , 103487. [CrossRef]

24. Maryam, L.; Khalid, S.; Ali, A.; Khan, A.U. Synergistic effect of doripenem in combination with cefoxitin and tetracycline in inhibiting NDM-1 producing bacteria. Future Microbiol. 2019, 14, 671-689. [CrossRef]

25. Carosso, S.; Miller, M.J. Syntheses and studies of new forms of N-sulfonyloxy $\beta$-lactams as potential antibacterial agents and $\beta$-lactamase inhibitors. Bioorg. Med. Chem. 2015, 23, 6138-6147. [CrossRef] [PubMed]

26. Santucci, M.; Spyrakis, F.; Cross, S.; Quotadamo, A.; Farina, D.; Tondi, D.; De Luca, F.; Docquier, J.-D.; Prieto, A.I.; Ibacache, C.; et al. Computational and biological profile of boronic acids for the detection of bacterial serine- and metallo- $\beta$-lactamases. Sci. Rep. 2017, 7, 17716. [CrossRef]

27. Groundwater, P.W.; Xu, S.; Lai, F.; Váradi, L.; Tan, J.; Perry, J.D.; Hibbs, D.E. New Delhi metallo- $\beta$-lactamase-1: Structure, inhibitors and detection of producers. Future Med. Chem. 2016, 8, 993-1012. [CrossRef]

28. Tooke, C.L.; Hinchliffe, P.; Bragginton, E.C.; Colenso, C.K.; Hirvonen, V.H.A.; Takebayashi, Y.; Spencer, J. $\beta$-Lactamases and $\beta$-Lactamase Inhibitors in the 21st Century. J. Mol. Biol. 2019, 431, 3472-3500. [CrossRef] [PubMed]

29. Krajnc, A.; Lang, P.A.; Panduwawala, T.D.; Brem, J.; Schofield, C.J. Will morphing boron-based inhibitors beat the $\beta$-lactamases? Curr. Opin. Chem. Biol. 2019, 50, 101-110. [CrossRef] [PubMed] 
30. Song, S.; Gao, P.; Sun, L.; Kang, D.; Kongsted, J.; Poongavanam, V.; Zhan, P.; Liu, X. Recent developments in the medicinal chemistry of single boron atom-containing compounds. Acta Pharm. Sin. B 2021, in press. [CrossRef]

31. Fernandes, G.F.S.; Denny, W.A.; Dos Santos, J.L. Boron in drug design: Recent advances in the development of new therapeutic agents. Eur. J. Med. Chem. 2019, 179, 791-804. [CrossRef] [PubMed]

32. Kahlert, J.; Austin, C.J.D.; Kassiou, M.; Rendina, L.M. The Fifth Element in Drug Design: Boron in Medicinal Chemistry. Aust. J. Chem. 2013, 66, 1118. [CrossRef]

33. Richardson, P.G.; Hideshima, T.; Anderson, K.C. Bortezomib (PS-341): A Novel, First-in-Class Proteasome Inhibitor for the Treatment of Multiple Myeloma and Other Cancers. Cancer Control 2003, 10, 361-369. [CrossRef]

34. Cahill, S.T.; Cain, R.; Wang, D.Y.; Lohans, C.T.; Wareham, D.W.; Oswin, H.P.; Mohammed, J.; Spencer, J.; Fishwick, C.W.G.; McDonough, M.A.; et al. Cyclic Boronates Inhibit All Classes of $\beta$-Lactamases. Antimicrob. Agents Chemother. 2017, 61, e02260-16. [CrossRef] [PubMed]

35. Cendron, L.; Quotadamo, A.; Maso, L.; Bellio, P.; Montanari, M.; Celenza, G.; Venturelli, A.; Costi, M.P.; Tondi, D. X-ray Crystallography Deciphers the Activity of Broad-Spectrum Boronic Acid $\beta$-Lactamase Inhibitors. ACS Med. Chem. Lett. 2019, 10, 650-655. [CrossRef] [PubMed]

36. Thomas, P.W.; Cammarata, M.; Brodbelt, J.S.; Fast, W. Covalent Inhibition of New Delhi Metallo- $\beta$-Lactamase-1 (NDM-1) by Cefaclor. ChemBioChem 2014, 15, 2541-2548. [CrossRef]

37. Lang, P.A.; Parkova, A.; Leissing, T.M.; Calvopiña, K.; Cain, R.; Krajnc, A.; Panduwawala, T.D.; Philippe, J.; Fishwick, C.W.G.; Trapencieris, P.; et al. Bicyclic Boronates as Potent Inhibitors of AmpC, the Class C $\beta$-Lactamase from Escherichia coli. Biomolecules 2020, 10, 899. [CrossRef]

38. Bader, R.F.W. Atoms in Molecules-A Quantum Theory; Oxford University Press: Oxford, UK, 1990.

39. Bader, R.F.W. A quantum theory of molecular structure and its applications. Chem. Rev. 1991, 91, 893-928. [CrossRef]

40. Levina, E.O.; Khrenova, M.G.; Astakhov, A.A.; Tsirelson, V.G. Revealing electronic features governing hydrolysis of cephalosporins in the active site of the L1 metallo- $\beta$-lactamase. RSC Adv. 2020, 10, 8664-8676. [CrossRef]

41. Khrenova, M.G.; Krivitskaya, A.V.; Tsirelson, V.G. The QM/MM-QTAIM approach reveals the nature of the different reactivity of cephalosporins in the active site of L1 metallo- $\beta$-lactamase. New J. Chem. 2019, 43, 7329-7338. [CrossRef]

42. Khrenova, M.G.; Nemukhin, A.V.; Tsirelson, V.G. Discrimination of enzyme-substrate complexes by reactivity using the electron density analysis: Peptide bond hydrolysis by the matrix metalloproteinase-2. Mendeleev Commun. 2020, 30, 583-585. [CrossRef]

43. Khrenova, M.G.; Tsirelson, V.G.; Nemukhin, A.V. Dynamical properties of enzyme-substrate complexes disclose substrate specificity of the SARS-CoV-2 main protease as characterized by the electron density descriptors. Phys. Chem. Chem. Phys. 2020, 22, 19069-19079. [CrossRef]

44. Khrenova, M.G.; Tsirelson, V.G. The N $\cdots H$ hydrogen bond strength in the transition state at the limiting step determines the reactivity of cephalosporins in the active site of L1 metallo- $\beta$-lactamase. Mendeleev Commun. 2019, 29, 492-494. [CrossRef]

45. Kim, S.; Chen, J.; Cheng, T.; Gindulyte, A.; He, J.; He, S.; Li, Q.; Shoemaker, B.A.; Thiessen, P.A.; Yu, B.; et al. PubChem in 2021: New data content and improved web interfaces. Nucleic Acids Res. 2021, 49, D1388-D1395. [CrossRef] [PubMed]

46. Word, J.M.; Lovell, S.C.; Richardson, J.S.; Richardson, D.C. Asparagine and glutamine: Using hydrogen atom contacts in the choice of side-chain amide orientation. J. Mol. Biol. 1999, 285, 1735-1747. [CrossRef] [PubMed]

47. Best, R.B.; Zhu, X.; Shim, J.; Lopes, P.E.M.; Mittal, J.; Feig, M.; MacKerell, A.D. Optimization of the Additive CHARMM All-Atom Protein Force Field Targeting Improved Sampling of the Backbone $\phi, \psi$ and Side-Chain $\chi_{1}$ and $\chi_{2}$ Dihedral Angles. J. Chem. Theory Comput. 2012, 8, 3257-3273. [CrossRef] [PubMed]

48. Denning, E.J.; Priyakumar, U.D.; Nilsson, L.; Mackerell, A.D. Impact of 2'-hydroxyl sampling on the conformational properties of RNA: Update of the CHARMM all-atom additive force field for RNA. J. Comput. Chem. 2011, 32, 1929-1943. [CrossRef]

49. Jorgensen, W.L.; Chandrasekhar, J.; Madura, J.D.; Impey, R.W.; Klein, M.L. Comparison of simple potential functions for simulating liquid water. J. Chem. Phys. 1983, 79, 926-935. [CrossRef]

50. Vanommeslaeghe, K.; Hatcher, E.; Acharya, C.; Kundu, S.; Zhong, S.; Shim, J.; Darian, E.; Guvench, O.; Lopes, P.; Vorobyov, I.; et al. CHARMM general force field (CGenFF): A force field for drug-like molecules compatible with the CHARMM all-atom additive biological force fields. J. Comput. Chem. 2010, 31, 671-690. [CrossRef] [PubMed]

51. Phillips, J.C.; Braun, R.; Wang, W.; Gumbart, J.; Tajkhorshid, E.; Villa, E.; Chipot, C.; Skeel, R.D.; Kalé, L.; Schulten, K. Scalable molecular dynamics with NAMD. J. Comput. Chem. 2005, 26, 1781-1802. [CrossRef]

52. Adamo, C.; Barone, V. Toward reliable density functional methods without adjustable parameters: The PBE0 model. J. Chem. Phys. 1999, 110, 6158. [CrossRef]

53. Grimme, S.; Antony, J.; Ehrlich, S.; Krieg, H. A consistent and accurate ab initio parametrization of density functional dispersion correction (DFT-D) for the 94 elements H-Pu. J. Chem. Phys. 2010, 132, 154104. [CrossRef]

54. Hehre, W.J.; Ditchfield, R.; Pople, J.A. Self-Consistent Molecular Orbital Methods. XII. Further Extensions of Gaussian-Type Basis Sets for Use in Molecular Orbital Studies of Organic Molecules. J. Chem. Phys. 1972, 56, 2257. [CrossRef]

55. Hariharan, P.C.; Pople, J.A. The influence of polarization functions on molecular orbital hydrogenation energies. Theor. Chim. Acta 1973, 28, 213-222. [CrossRef]

56. Valiev, M.; Bylaska, E.J.; Govind, N.; Kowalski, K.; Straatsma, T.P.; Van Dam, H.J.J.; Wang, D.; Nieplocha, J.; Apra, E.; Windus, T.L.; et al. NWChem: A comprehensive and scalable open-source solution for large scale molecular simulations. Comput. Phys. Commun. 2010, 181, 1477-1489. [CrossRef] 
57. Seritan, S.; Bannwarth, C.; Fales, B.S.; Hohenstein, E.G.; Isborn, C.M.; Kokkila-Schumacher, S.I.L.; Li, X.; Liu, F.; Luehr, N.; Snyder, J.W.; et al. TeraChem: A graphical processing unit-accelerated electronic structure package for large-scale ab initio molecular dynamics. WIREs Comput. Mol. Sci. 2020. [CrossRef]

58. Melo, M.C.R.; Bernardi, R.C.; Rudack, T.; Scheurer, M.; Riplinger, C.; Phillips, J.C.; Maia, J.D.C.; Rocha, G.B.; Ribeiro, J.V.; Stone, J.E.; et al. NAMD goes quantum: An integrative suite for hybrid simulations. Nat. Methods 2018, 15, 351-354. [CrossRef]

59. Khrenova, M.G.; Kulakova, A.M.; Nemukhin, A.V. Light-Induced Change of Arginine Conformation Modulates the Rate of Adenosine Triphosphate to Cyclic Adenosine Monophosphate Conversion in the Optogenetic System Containing Photoactivated Adenylyl Cyclase. J. Chem. Inf. Model. 2021, 61, 1215-1225. [CrossRef] [PubMed]

60. Humphrey, W.; Dalke, A.; Schulten, K. VMD: Visual molecular dynamics. J. Mol. Graph. 1996, 14, 33-38. [CrossRef]

61. Lu, T.; Chen, F. Multiwfn: A multifunctional wavefunction analyzer. J. Comput. Chem. 2012, 33, 580-592. [CrossRef]

62. Bartashevich, E.V.; Troitskaya, E.A.; Tsirelson, V.G. The N ․ I I halogen bond in substituted pyridines as viewed by the source function and delocalization indices. Chem. Phys. Lett. 2014, 601, 144-148. [CrossRef]

63. Gatti, C.; Cargnoni, F.; Bertini, L. Chemical information from the source function. J. Comput. Chem. 2003, 24, 422-436. [CrossRef] [PubMed]

64. Bader, R.F.W.; Gatti, C. A Green's function for the density. Chem. Phys. Lett. 1998, 287, 233-238. [CrossRef]

65. Hirshfeld, F.L. Bonded-atom fragments for describing molecular charge densities. Theor. Chim. Acta 1977, 44, 129-138. [CrossRef]

66. Liu, S.; Rong, C.; Lu, T. Information Conservation Principle Determines Electrophilicity, Nucleophilicity, and Regioselectivity. J. Phys. Chem. A 2014, 118, 3698-3704. [CrossRef]

67. Roy, R.K. Stockholders Charge Partitioning Technique. A Reliable Electron Population Analysis Scheme to Predict Intramolecular Reactivity Sequence. J. Phys. Chem. A 2003, 107, 10428-10434. [CrossRef]

68. Oláh, J.; Van Alsenoy, C.; Sannigrahi, A.B. Condensed Fukui Functions Derived from Stockholder Charges: Assessment of Their Performance as Local Reactivity Descriptors. J. Phys. Chem. A 2002, 106, 3885-3890. [CrossRef]

69. Khrenova, M.G.; Kulakova, A.M.; Nemukhin, A.V. Proof of concept for poor inhibitor binding and efficient formation of covalent adducts of KRAS G12C and ARS compounds. Org. Biomol. Chem. 2020, 18, 3069-3081. [CrossRef]

70. Khrenova, M.G.; Nemukhin, A.V. Modeling the Transient Kinetics of the L1 Metallo- $\beta$-Lactamase. J. Phys. Chem. B 2018, 122, 1378-1386. [CrossRef]

71. Vasilevskaya, T.; Khrenova, M.G.; Nemukhin, A.V.; Thiel, W. Mechanism of proteolysis in matrix metalloproteinase-2 revealed by QM/MM modeling. J. Comput. Chem. 2015, 36, 1621-1630. [CrossRef]

72. Carroll, M.T.; Cheeseman, J.R.; Osman, R.; Weinstein, H. Nucleophilic addition to activated double bonds: Predictions of reactivity from the Laplacian of the charge density. J. Phys. Chem. 1989, 93, 5120-5123. [CrossRef]

73. Jin, J.-L.; Li, H.-B.; Lu, T.; Duan, Y.-A.; Geng, Y.; Wu, Y.; Su, Z.-M. Density functional studies on photophysical properties and chemical reactivities of the triarylboranes: Effect of the constraint of planarity. J. Mol. Model. 2013, 19, 3437-3446. [CrossRef] [PubMed] 